\title{
Sustainable resilience for small farmers: the best way to protect food security
}

\author{
Mihai DORNEANU \\ Bucharest University of Economic Studies, Bucharest, Romania \\ director.neamt@apia.org.ro \\ Ioan-Radu PETRARIU \\ Bucharest University of Economic Studies, Bucharest, Romania \\ radu.petrariu@rei.ase.ro
}

\begin{abstract}
In the past years, the food industry has been challenged by several factors: increased natality, accelerated growth of urban areas, higher prices. All the above are turning into a growth vector which may seem like a great opportunity for farm owners. Despite the favorable context, the farmers are facing their own issues trying to cover a big demand, through eco-friendly ways. This paper explains the importance of ensuring resilience for small farmers. In general, farmers are adaptive entrepreneurs, but they need support through agricultural policies, a coherent legislative framework, and a substantial package of economic measures. The modern Romanian farmer will be able to streamline their supply once they learn how to optimize their sustainable business plans. The increased yields are determined by both technological processes and responsibility for the environment. Promoting small farmers and stimulating their access to the market is defining for the future of food security.
\end{abstract}

Keywords: food security, food safety, sustainable agriculture, small farmers, young farmers, smart regulations, resilience, entrepreneurship, Farm to Fork Strategy.

\section{Introduction}

Starting from the primary need for food which is the body's need to feed itself with specific nutrients to generate energy and ensure the functioning of organs, the main concern of people is to have access to safe, healthy, and best quality food because the state of physical, mental and even spiritual health is closely correlated with nutrition.

Agriculture plays an essential role in sustaining the increased demand for food. However, several aspects lead to the decrease in the flow of food needed for a constantly growing global population: the accelerated growth of urban areas, the even higher prices on the input market, the constant pressure on water resources, the vulnerability of crops, animals and the environment due to obvious climate change that visibly disrupts certain natural balances.

Thus, if we follow the current rate of exponential growth of food demand, corroborated with population growth, we can make predictions that show that by 2050 food demand will increase by $70 \%$, emerging countries being those that contribute the most to this trend ${ }^{1}$.

Although this growth vector seems like an opportunity for farm owners, it is actually a primary challenge how to cover such a demand in a sustainable way while respecting the climate parameters. In the context of climate change, improving global food security leads to adequate crops being grown in the most productive places.

\footnotetext{
${ }^{1}$ Food and Agriculture Organization of the United Nations The State of the World's Land and Water Resources for Food and Agriculture; Managing Systems at Risk, Rome, 2011.
} 
The EU's objectives guarantee a high level of protection of human life and health and the protection of consumers' interests, guarantee fair trade practices in the food sector, and take the environment into account.

The European Commission facilitates food security through an improved legislative framework that covers all aspects of the food with a central element of the European Green Pact defined in the Farm to Fork Strategy.

The process of integrating food into the market is a comprehensive approach of wellestablished issues and principles at both the national and international levels.

Respectful cooperation in human interaction with the environment and natural resources is based on the principle of quality. Farmers maintain the health of crops and varieties using natural fertilizers and intelligent crop rotation systems. All these measures are taken to protect the sensitive ecological balance.

In order to protect food security and food safety, one of the main points of maintaining agriculture is to ensure the resilience of small farmers. Promoting small farmers and stimulating their access to the market helps to increase the availability of safe food so that the prosperity of products to ensure our daily food needs.

The basic food needs aim at purchasing it at the lowest possible prices and through the marketing perspective it influences the agri-food market, so supporting small farmers at all levels of production is an added value for the evolutionary process of food needs.

\section{Small farmers ,community”}

A relevant definition would include small farmers in the category of persons who have the right of ownership and/or right of use for an agricultural holding, no matter the age.

According to statistics, only $11 \%$ of agricultural holdings in the European Union are managed by farmers under the age of 40 - and young people find it difficult to be persuaded to become farmers. Agriculture must develop as a whole activity with support measures dedicated to persons up to 40 years old to encourage this segment of society to come with enthusiasm, attention, and innovations to the field (FAO, 2011).

In Romania, most individual farms (small farmers) have low economic power and are largely oriented towards self-consumption. Small farms represent a significant percentage of all existing holdings (Bold, 2001). Opening to the market is relatively small, both in terms of outputs and inputs. Thus, small farmers have a diversified production structure, determined by the needs of the household, as well as by a reduced and inadequate technical endowment, which prevents the increase of productivity and obtaining a surplus of products for sale.

The small farmer, according to Regulation (EU) no. 1307/2013 art. 61-64 and the Government Emergency Ordinance no. 3/2015, art. 26 - paragraph (1), is defined as: "The farmer who submits a single payment request in 2015 according to the provisions of art. 8 para. (2), is eligible for the single area payment scheme and is entitled to an annual payment of a maximum of EUR 1,250, depending on the area and/or a number of eligible animals kept on the holding, is automatically included in the simplified scheme for small farmers."

Briefly analyzing the way, the agricultural area in our country is managed, we notice that it is divided between farms with a considerable agricultural heritage and farmers that fall into the above definition, the middle sector being almost non-existent, this trend is visible at the European level only for the members who have just joined the European Union. 
This situation underlines the complexity of the socio-economic framework in regards to the agricultural and rural sector in Romania, but also the opportunities that can open once the structural problems are solved.

Improving the economic performance of all smallholder farms would support the diversification of agricultural production and stimulate increased participation in the agricultural market. The development of large farms has created a monopoly on agribusiness, and one of the solutions would be to consolidate and stimulate small farms to be market-oriented.

The share of farmers registers a decreasing trend from one agricultural campaign to another, as a result of the merging of agricultural areas, Romania being known for the massive fragmentation of land, and the consolidation process is natural and necessary for the transition from modern to high-performance agriculture.

Thus, an eloquent example, if we take as a reference the first years after Romania's accession to the European Union, the number of farms decreased by 400.000 , but the number of young farmers increased from $17 \%$ to $23 \%$, an aspect that can signal a revival of the agricultural spectrum that has become of interest for certain social categories that have anticipated the opportunities it can generate and the agricultural capacity of Romania that can meet the growing needs for food.

Individual (family) farms remain the best means of ensuring the viability of food production, the sustainable management of natural resources, and the preservation of an authentic rural life.

\section{Current possibility of financing}

Romanian farmers get direct support from the European Union and from national funds through the Agency for Payments and Interventions for Agriculture in accordance with the Common Agricultural Policy. Every year applications submitted by over 1 million farmers are processed. Through the mechanisms and instruments of the Common Agricultural Policy, the absorption of European and national financial aid was $98 \%$ through 45 payment schemes / aid granting measures, comprising 89 sub-measures, respectively packages / sub-packages.

Of all these, the measure which is strictly designed for small farmers has been regulated under Regulation (EU) no. 1307/2013 art. 61-64 and the Emergency Ordinance no. 3/2015, which stipulates certain advantages that they have and that have the role of encouraging production, within the limits of their capabilities, being exempted from certain mandatory requirements for persons with larger areas of land, such as the scheme extends for a period of 5 years but there is the possibility of withdrawal at any time, they are not obliged to declare their entire agricultural area if they do not apply for support for those lots, they are exempted from using agricultural practices beneficial to climate and environment, no administrative sanctions are applied for noncompliance with cross-compliance rules. All these advantages have the role of encouraging and maintaining these farms with small areas in the agricultural circuit.

Even though there are many types of programs / measures, the eligibility conditions are not met by most small farmers. Funding that farmers could benefit from involves criteria set by EU law and regulations that provide support in relation to certain eligibility conditions that are impossible for some people, which influences the blocking of productive potential and improving the financial capacity of small farmers.

The possibility of accessing already available funding programs / measures is impossible for small farmers who have a low level of education, have not completed technological education 
or their financial capacity does not meet their eligibility criteria, which leads to decreased development.

In order to avoid certain risks, such as abandonment of agricultural land, with negative economic and environmental effects, impoverishment of older people in rural areas who can no longer work their land, the yield of agricultural production should remain low although potential Romania's agricultural sector is obvious, agricultural policies must be developed that are in line with the requirements of farmers, on all three constituent levels: large, medium and small farms.

\section{Creating a sustainable support system for small farmers}

Given the extensive seasonal nature of agricultural activities, economic diversification by creating a new support system can generate investment potential for small producers. In order to create a feasible financing system for small farmers, an external source of sustainable and accessible financing would be to redirect a percentage of $2 \%$ or $3.5 \%$ of the annual tax.

Currently, a financial support mechanism is presented in Law 227/2015 on the Fiscal Code, with subsequent amendments and completions, based on Order 15/2021 for the approval of the Procedure for establishing the amount representing up to $3.5 \%$ of the annual tax due to support nonprofits it is established and operates under the conditions of the law and the cult units, as well as for the granting of private scholarships, according to the law.

Starting and implementing a new system that generates external income for small farmers could be achieved through a proposal for a legislative amendment and the creation of a legal framework for the redirection of income tax to benefit small farmers. Sustainable development is a defining factor, and this system of support measures would be a sustainable support technique for the activity of small farmers in the agri-food market (EC, 2012).

Facilitating the creation of such a system would economically and socially improve the quality of life by building a favorable environment to help consumers to the community of small farmers, strengthening the legislative framework "Farm to Fork" of food safety allowed by the European Commission (Fésüs et al., 2008).

A sustainable system requires a set of united procedures with a more complex structure and functionality specific to agricultural activity. Thus, the proposal is based on two alternatives for redirecting income tax for small farmers:

1. Redirect $2 \%$ for farmers working in a single agricultural sector;

2. Redirection of $3.5 \%$ for farmers operating in at least 2 agricultural sectors or farmers that produce organic (bio) products.

The construction of such a system might be challenging for small farms. On one hand, a complex redirection system offers a higher degree of productive potential, and on the other hand, it is a broader representation that provides the consequences and utilities of the implementation methods.

The methodology for developing the system and the rules for applying the redirection will be subject to the legislation in force, respectively the Fiscal Code.

The National Agency for Fiscal Administration manages according to the law the redirection of up to $3.5 \%$ from the annual tax due by taxpayers to support the categories already mentioned, being an already known field it is not necessary to train the staff of the competent institutions. 
In addition to the IT system and for the efficient management of the amounts, a collaboration agreement can be concluded between National Agency for Fiscal Administration and the Agency for Payments and Interventions for Agriculture, through which the distribution of the amounts can be verified and carried out in accordance with the documents / file of each farmer in relation to the application.

The amounts coming from these external sources would bring many benefits to small farmers, who would find individual solutions to streamline the production process, the possibility of investment, the performance of human capital. All these aspects would lead to the efficient management of the agricultural area and to a higher level of productivity.

\section{Conclusion}

The modern Romanian farmer, connected to the requirements of 21st-century agriculture, should always be updated with the innovation that constantly appears, representing an opportunity to considerably improve the production capacity.

Next, the farmer should find financial resources in order to build an ambitious but sustainable business plan, and he should be aware of the agricultural heritage that our country has and that can propel it among the most important agricultural producers in the world. The next concern is increasing its yields, looking for solutions to continuously improve technological processes, and last but not least, he should show responsibility for new environmental requirements.

In order to transform the scheme described above into reality, farmers must benefit from agricultural policies in line with European agricultural visions, a coherent legislative framework but also a predictable and substantial package of economic measures, to make accessible the course and their projection towards reaching those essential points in the potentiation of this fundamental field.

Sustainable development consists in balancing local and global efforts to meet basic human needs, without destroying or degrading the natural environment, so the system created becomes sustainable because it is characterized by a balance that improves the quality of human life over time, through action in continuous development.

Farmers are adaptive entrepreneurs who need reliable markets for their crops and consumers in all areas. The creation of a sustainable, stable, secure system with existing resources following national and European legislation, as well as the example of other systems implemented, allows rapid access to income from external sources for small farmers, allows the development of European Commission policies through the Common Agricultural Policy and has national-level security.

\section{References}

Bold, I. (2001). Agricultural exploitation, organization, development and exploitation. Timişoara: Mirton Publishing House.

FAO (2011). The State of the World's Land and Water Resources for Food and Agriculture: Managing Systems at Risk. Rome: Food and Agriculture Organization of the United Nations and London: Earthscan. Retrieved from http://www.fao.org/3/i1688e/i1688e.pdf.

European Commission (2012). Prospects for Agricultural Markets and Income in the EU 2012-2022. Retrieved from http://ec.europa.eu/agriculture/markets-and-prices/ mediumterm-outlook/2012/fullrep_en.pdf. 
Fésüs, G, Rillaers, A., Poelman, H., and Gáková, Z. (2008). Regions 2020. Demographic Challenges for European Regions. Background document to Commission Staff Working Document Sec. (2008), 2868 Final Regions 2020, An Assessment of Future Challenges for EU Regions.

PICBE |

569

DOI: $10.2478 /$ picbe-2021-0052, pp. 564-569, ISSN 2558-9652 |

Proceedings of the $15^{\text {th }}$ International Conference on Business Excellence 2021 